Cómo citar este artículo en MLA: Molina Peláez, T. "Montaigne y Burckhardt como fuentes de la doctrina reaccionaria en los Escolios de Nicolás Gómez Dávila”. Escritos 27.58 (2019):

49-69. doi: http://dx.doi.org/10.18566/escr.v27n58.a03

Fecha de recepción: 04.12 .2018

Fecha de aceptación: 24.04 .2019

\title{
Montaigne y Burckhardt como fuentes de la doctrina reaccionaria en los Escolios de Nicolás Gómez Dávila
}

\section{Montaigne and Burckhardt as Sources of Nicolas Gomez Davila's Reactionary Doctrine in Scholia}

\section{Montaigne e Burckhardt como fontes da doutrina reacionária nos escólios de Nicolás Gómez Dávila}

\author{
Tomás Felipe Molina Peláez ${ }^{1}$
}

\section{RESUMEN}

Muchos de los comentaristas de Gómez Dávila han notado que el carácter de su obra es intertextual, es decir, que no es un sistema cerrado: siempre está conectado implícitamente con otros libros y pensadores. El mismo Gómez Dávila nos indica en sus Escolios que Montaigne y Burckhardt tienen un rol central en esta intertextualidad. El siguiente artículo se propone interpretar la conexión entre los

1 Candidato a Doctor en Filosofía por la Universidad de Granada, España. Profesor Asociado de la Universidad Gran Colombia. Correo electrónico: tomas.molina123@ gmail.com. 
dos pensadores mencionados y la obra del colombiano. En el caso de Burckhardt, se mostrará cómo su pesimismo antropológico basado en una idea del pecado original, su escepticismo sobre la posibilidad humana de construir utopías, su negación de la idea de progreso y su concepción del tamaño y el papel del Estado aparecen y se desarrollan en el pensamiento del colombiano. En el caso de Montaigne, se mostrará su cercanía con Gómez Dávila a partir de sus similitudes biográficas, su alejamiento del espíritu académico de sus propios tiempos, su concepción de la filosofía, su escepticismo como arma para defender la fe y su fuerte conservatismo. Finalmente, se concluirá que esta intertextualidad que el autor mismo señala en su confesión sobre Montaigne y Burckhardt nos ayuda a darle orden y sentido a sus posiciones políticas en los Escolios. En efecto, se intentará mostrar que Gómez Dávila articula las influencias de sus maestros para concluir en una visión de mundo reaccionaria.

\title{
Palabras clave:
}

Nicolas Gómez Dávila, Michel de Montaigne, Jacob Burckhardt, intertextualidad, reaccionario, filosofía latinoamericana.

\begin{abstract}
Some of Gomez Davila's commentators have noticed that his work has an intertextual nature, that is, it is not a closed system: it is always implicitly linked to other works and writers. Gomez Davila himself points out in the Scholia that Montaigne and Burckhardt play a significant role in such intertextuality. The purpose of the article is to present an interpretation of the link of the aforementioned writers with the work of the Colombian one. In Burckhardt's case, it is shown how his anthropological pessimism - based on an idea of the original sin-, his skepticism regarding the human possibility of constructing utopias, his denial of the idea of progress, and his conception of the size and role of the State are found in the work of Gomez Davila, as well as the way in which the latter develops them. In Montaigne's case, his closeness to Gomez Davila is shown by means of their biographical similarities, their distance to the academic world of their own time, their own idea of philosophy, their use of skepticism as a tool to defend faith, and their strong conservatism. The article concludes that this intertextuality provides order and sense to Gomez Davila's political standpoint within his Scholia. Indeed, it is intended to show that Gomez Davila articulates the influence of his masters in a reactionary view of the world.
\end{abstract}

\section{Key Words:}

Nicolas Gomez Davila, Michel de Montaigne, Jacob Burckhardt, Intertextuality, Reactionary, Latin American Philosophy.

\section{RESUMO}

Muitos dos comentaristas de Gómez Dávila têm assinalado o caráter intertextual de sua obra, isto é, sua obra não é um sistema fechado: ela sempre está ligada implicitamente com outros livros e pensadores. Nos seus Escólios, o mesmo Gómez Dávila nos indica que Montaigne e Burckhardt têm um papel central nessa intertextualidade. $\mathrm{O}$ seguinte artigo tenta interpretar a conexão entre esses dois 
pensadores e a obra do colombiano. No caso de Burckhardt, o artigo mostrará como seu pessimismo antropológico, baseado em uma ideia do pecado original, seu ceticismo sobre a possibilidade humana de construir utopias, sua negação da ideia de progresso e sua conceição do tamanho e o papel do Estado aparecem e se desenvolvem no pensamento do colombiano. No caso de Montaigne, o texto mostrará sua proximidade com Gómez Dávila a partir de suas semelhanças biográficas, seu afastamento do espirito acadêmico de seus próprios tempos, sua conceição de filosofia, seu ceticismo como arma para defender a fé e seu forte conservadorismo. Finalmente, conclui-se que essa intertextualidade - que o autor assinala em sua confissão sobre Montaigne e Burckhardt - nos ajuda a ordenar e dar sentido a seus posicionamentos nos Escólios. Efetivamente, estabelece-se que Gómez Dávila articula as influências de seus mestres para concluir em uma visão reacionária do mundo.

\section{Palavras chave:}

Gómez Dávila, Montaigne, Burckhardt, intertextualidade, reacionário, filosofia da América latina. 


\section{Introducción}

L

os Escolios a un texto implícito son el magnum opus de Nicolás Gómez Dávila.

$\mathrm{Su}$ estilo fragmentario, sin embargo, impone una serie de dificultades

hermenéuticas que sus comentaristas han intentado superar poco a poco. Una de las más importantes podríamos sintetizarla así: el fragmento ostenta, pero no sustenta. Es decir, en el escolio aparece una dura punta de diamante, pero no el proceso orgánico y argumentativo que le dio origen y que lo justifica.

Una de las maneras de acercarse a esta problemática es por medio de la lógica intertextual. Lo anterior implica asumir que el escolio no es completamente autónomo, sino que siempre incluye otros textos con los que habla. En otras palabras, los escolios están en relación dialógica - no necesariamente subordinada - con otras obras. Esta aproximación interpretativa está inspirada en el mismo autor cuando nos dice que sus escolios se refieren siempre a un texto implícito; nos señala que su libro no es plenamente autónomo, es decir, que está necesariamente conectado con otros libros. Descubrir cómo y con cuáles es una tarea que los comentaristas de Gómez Dávila deben hacer si están de acuerdo con esta aproximación.

Entre los trabajos que ya han explorado la intertextualidad en la obra de Gómez Dávila - aunque sea de manera implícita - podemos encontrar el importante artículo de Mauricio Galindo "Un pensador aristocrático en los Andes: una mirada al pensamiento de Nicolás Gómez Dávila”. Allí nos cuenta, por ejemplo, de cómo la escuela histórica alemana influenció el pensamiento del colombiano. Los artículos de Michael Rabier "La cuestión literaria en la obra de Gómez Dávila", "Nicolás Gómez Dávila y las paradojas del conservadurismo" y "Biblioteca gomezdaviliana: las fuentes bibliográficas del pensamiento de Nicolás Gómez Dávila” han sido importantísimos trabajos desde la perspectiva intertextual, pues muestran la relación del filósofo colombiano con el conservadurismo, el liberalismo, la contrailustración y otros movimientos que lo influenciaron. El artículo de Verhelst y Raga sobre las similitudes entre el escepticismo de Montaigne y el escepticismo que Gómez Dávila desarrolla en Notas, es un importante precedente del presente escrito. Finalmente, son muy importantes los comentarios que Abad hace a propósito de la intertextualidad. En su libro Pensar lo implícito: en torno a Gómez Dávila explica que la relación de la escritura del colombiano con los textos de sus maestros no es la de un mero comentarista subordinado, sino que hay un proceso hermenéutico por 
medio del cual el autor se apropia del texto que comenta. Esto deriva en una obra auténtica del escoliasta mismo (147).

Ahora bien, el aporte de este artículo a la aproximación intertextual es el de conectar los Escolios con quienes el autor mismo reconocía como sus santos patrones: Montaigne y Burckhardt (Escolios I 428). Se pretende mostrar, por tanto, cómo las ideas políticas que aparecen en los Escolios están conectadas con el francés y el suizo. La idea es que el reaccionarismo de Gómez Dávila es consecuencia - al menos en parte - de la suma de las ideas de Burckhardt y Montaigne. Dos observaciones animan lo anterior. Inicialmente, ya Franco Volpi señalaba que ambos tienen un peso muy grande en las ideas del colombiano, dada su importancia intelectual: el primero es el maestro de la historia y el segundo el del escepticismo (61). Esto es fundamental en un pensador que, como Gómez Dávila, comenta constantemente la historia desde una perspectiva pesimista y escéptica. En segundo lugar, la expresión que el colombiano utiliza para referirse a sus maestros es muy particular. Los santos patrones son intercesores y abogados de uno mismo ante Dios. Eso quiere decir que saben de lo que uno habla, i.e., lo entienden. De otro modo no podrían defenderlo. Al mismo tiempo, uno se identifica con ellos, tiene confianza en lo que dicen. No es solo, por tanto, que sean sus maestros, sino que el colombiano se identifica y confía íntimamente en ellos. Así pues, las ideas de Gómez Dávila tienen que ser consecuencia -al menos parcialmente- de lo que Montaigne y Burckhardt dijeron.

Para cumplir el propósito anteriormente señalado, se identificarán las ideas principales que conectan al suizo y al francés con el colombiano. En el caso del primero, se mostrará cómo su pesimismo antropológico basado en una idea del pecado original, su escepticismo sobre la posibilidad humana de construir utopías, su negación de la idea de progreso y su concepción del tamaño y el papel del Estado, aparecen y se desarrollan, aunque con pequeñas diferencias, en el pensamiento del colombiano. En el caso del segundo, se mostrará su cercanía a partir de sus similitudes biográficas, su alejamiento del espíritu académico de sus propios tiempos, su concepción de la filosofía, su escepticismo como arma para defender la fe y su fuerte conservatismo. Finalmente, se concluirá que esta intertextualidad que el autor mismo señala en su confesión sobre Montaigne y Burckhardt nos ayuda a darle orden y sentido a sus posiciones políticas en los Escolios. En efecto, se intentará mostrar que Gómez Dávila articula las influencias de sus maestros para concluir en una visión de mundo reaccionaria. 


\section{Burckhardt}

Como es bien sabido, Jacob Burckhardt fue uno de los historiadores más importantes del siglo XIX, especialmente por su obra sobre el Renacimiento italiano. Tal vez no es tan conocido el hecho de que el suizo era un duro crítico de la modernidad. El pensamiento de Burckhardt se caracterizaba por un gran pesimismo heredado de la idea de un pecado original (Roderick, 114). Eso lo conecta de manera clara con el colombiano. Aunque el suizo era protestante y Gómez Dávila católico, sus ideas sobre las consecuencias de la caída no son muy diferentes. Coinciden en la idea básica: gracias al pecado original no hay armonía total entre los hombres - ni entre hombres y mujeres- y tampoco se puede conseguir. Estamos condenados a cierto grado de conflicto. Ni siquiera hay armonía entre el alma y el cuerpo mismo de los seres humanos. Hay una inclinación casi irresistible hacia el mal que ningún grado de ingeniería social puede curar. Nuestra voluntad, en suma, está dañada. Podemos desear cosas que nuestra razón no quiere que deseemos. Así pues, el hombre es incapaz de la perfección.

Este pesimismo antropológico es la piedra angular de la crítica de Burckhardt y de Gómez Dávila a la modernidad, en tanto es la fuente de su desconfianza frente a la idea de que el hombre puede construirse a sí mismo una sociedad perfecta, o como mínimo, una sociedad donde el hombre pueda ser mucho mejor. El historiador suizo condenaba las ideas de Rousseau, por ejemplo, según las cuales era posible construir un régimen en el que la naturaleza humana se tornaría buena (Burckhardt, Judgments 250). Para Gómez Dávila también es una necedad considerar que la naturaleza humana es o puede llegar a ser buena con las instituciones correctas; y mucho menos por un cambio brusco. Todo lo contrario y por eso decía: "inútil, como una revolución" (Escolios II 126). El día después de la revolución se repetirán los mismos errores del pasado, porque la naturaleza humana caída es una constante en la historia. De hecho, hay una tendencia al mal en todos nosotros, incluyendo al mismo Gómez Dávila. Como dice, "nadie me inducirá a absolver la naturaleza humana porque me conozco a mí mismo" (Escolios I 287).

El pesimismo de Burckhardt se extendía a todas las épocas. Por eso nos dice con toda franqueza que debemos entender que nunca ha habido ni habrá eras doradas, aunque debemos reconocer en el pasado nuestros nobles propósitos (Judgments 3). Gómez Dávila está de acuerdo: aunque el pasado 
tuvo momentos brillantes, no contiene sueños. La realidad humana siempre ha sido miserable. En el futuro no se puede esperar que este estado de cosas vaya a cambiar, porque no hay nada en la naturaleza caída del hombre que lo permita. Puede haber fortuna, puede haber una conjunción de elementos históricos que produzcan un momento brillante, pero las utopías son imposibles, el progreso no existe. El hombre, de hecho, tiende hacia la barbarie. Esto ya lo había visto Martin Mosebach cuando señalaba que para Gómez Dávila "la historia lo llevó sobre unos cuantos puntos altos, pero sobre todo a través de valles, pantanos y abismos" (2017).

Rechazar la premisa antropológica de la Ilustración mediante la idea del pecado original lleva al suizo y al colombiano a condenar con toda claridad la idea de progreso. Burckhardt atacaba la idea de que la razón podía progresivamente crear un mundo mejor a partir del camino moderno. Caracterizaba el progreso como la propuesta de que tal o cual pasillo es el más bello solo porque lleva a nuestra habitación (Burckhardt, Judgments 79). Para Gómez Dávila la idea de progreso es igualmente ingenua: "el progreso se reduce finalmente a robarle al hombre lo que lo ennoblece, para poder venderle barato lo que lo envilece" (Escolios II 60). Justo porque el hombre tiende hacia el mal, la razón misma que la Ilustración considera esencial para el progreso, se puede poner en nuestra contra para esclavizarnos, llenarnos de orgullo y hacernos olvidar las evidencias de lo trascendente. Eso no es precisamente progresar, en opinión del colombiano. Una razón progresista que se olvida de Dios nos atonta, y quizá por eso Gómez Dávila decía que "el costo del progreso se computa en tontos" (Nuevos escolios 57). Es decir, para progresar se precisa aumentar la cantidad de idiotas, de hombres esclavizados por una razón inmanente que solo se admira a sí misma.

Que ambos rechacen el progreso no quiere decir, sin embargo, que acepten una visión estática de la historia. Para Burckhardt, "[...] el cambio ocurría en los mundos materiales y espirituales [...] pero eso no se traducía necesariamente en un progreso histórico o moral/intelectual. La visión progresista de la sociedad ofrecida por la filosofía liberal no era más que un autoengaño" (Roderick 116). Gómez Dávila está de acuerdo. En el mundo material uno puede ver grandes cambios: justo por eso la sociedad tradicional fue destruida y reemplazada por la moderna. En el mundo espiritual también hay cambios: uno puede leer la historia como el proceso en el que una "súbita experiencia religiosa $[\ldots]$ propaga un tipo humano nuevo;" para luego ver el "lento 
proceso de desmantelamiento del tipo" (Gómez Dávila, Sucesivos escolios 16). Y no obstante, pese a que haya cambios, no hay progreso como lo entiende la modernidad. Como mucho puede decirse que "dudar del progreso es el único progreso" (Escolios I 109). La historia puede cambiar radicalmente, pero siempre hay una constante: la condición caída del hombre.

Ninguno de los dos censura el cambio en sí mismo, pues es consustancial a la historia. El progreso, en cambio, sí es censurable en tanto demanda el rechazo del pasado como inherentemente defectuoso. Para Gómez Dávila eso es problemático, pues ese rechazo implica que debemos empezar de nuevo, es decir, debemos romper con ese pasado que nos ata a una serie de errores para poder progresar. Pero como nos dice en los Escolios II, "todo lo que interrumpa una tradición obliga a principiar de nuevo. Y todo origen es sangriento" (267). De ahí que, en opinión del bogotano, las revoluciones progresistas siempre tengan un gran número de muertos. Quizá también las restauraciones, en todo caso. Por eso "el reaccionario no anhela la vana restauración del pasado, sino la improbable ruptura del futuro con este sórdido presente" (278).

En efecto, puesto que toda restauración es imposible en cuanto sus elementos pertenecen a un pasado muerto, el reaccionario colombiano solo puede esperar el improbable evento de que el futuro sea distinto. Burckhardt, empero, reconocía que en ciertos casos las restauraciones de regímenes eran posibles, aunque peligrosas. En sus Reflexiones sobre la historia universal dice que "puede ocurrir que representen de por sí una restauración de la justicia y hasta una restauración de la totalidad de la nación hasta entonces interrumpida, pero en la práctica son exactamente tanto más peligrosas cuanto mayor amplitud haya tenido la crisis cuyo ciclo vienen a cerrar" (242). En definitiva, aquí se puede intentar restaurar algo del pasado. No obstante, puesto que las condiciones históricas han cambiado ya, toda restauración implica siempre un peligro. Es imposible devolver completamente la rueda de la historia: se deben aceptar hasta cierto punto los cambios que ella trae. De aquí surge una resignación frente a la modernidad que ambos pensadores comparten.

Burckhardt y Gómez Dávila también compartían elementos importantes en su concepción del Estado. Como explica Roderick, el historiador suizo condenaba los estados fuertes y "creía que el estado no era una entidad moral, la formación de la cual tenía un propósito divino de desarrollo histórico y que era necesaria para 
la realización de verdadera libertad intelectual e individual, ni un repositorio de valores éticos" (121). En "De Iure" (2017), Gómez Dávila confirma su influencia de Burckhardt cuando dice, siguiendo la idea anterior, que:

La legitimidad del estado no depende de exigencias éticas, sociales, o políticas.

[...]. Todo estado que resulte del acuerdo concluido entre quienes gobiernan, y que administre el derecho que estos reconocen, es jurídicamente válido. El estado de derecho reviste aspectos múltiples. La historia es el antifonario policromo de sus variaciones melódicas (47).

En efecto, para ambos el Estado no es un repositorio de valores éticos, ni una entidad moral. La función del Estado es principalmente la aplicación del derecho. Su legitimidad no depende, entonces, de la realización de propósitos morales. Es más, debe evitarla. Por eso dice Burckhardt que "el hecho de que el estado pretenda realizar directamente lo moral, cosa que solo puede y debe hacer la sociedad, constituye una degeneración y una presunción burocráticofilosófica” (Reflexiones 80). Y Gómez Dávila confirma estos juicios del suizo cuando sostiene en los Escolios que "pedirle al estado lo que solo debe hacer la sociedad es el error de la izquierda" (50). No obstante, al menos en su teoría del origen del Estado, el suizo y el colombiano difieren. Para Burckhardt el estado nace principalmente del ejercicio de la coerción y del poder. En cambio, para el colombiano el origen del estado va más allá de su mera realidad positiva y coercitiva. Según Gómez Dávila, el estado tiene un origen jurídico y solo a partir de él puede surgir el ejercicio de la coerción y el poder. El estado nace para que obedezcamos al derecho que hemos pactado (Gómez Dávila, 2017). Burckhardt, en todo caso, abogaba por un estado limitado: su función principal, como en Gómez Dávila, es que obedezcamos la regla de derecho. En consecuencia, prefería un estado no intervencionista que "por medio del ejercicio y el mantenimiento del imperio de la ley regulara intereses que competían dentro de la sociedad y proveyera seguridad básica para el individuo" (Roderick 123). Para Burckhardt, ese estado no solo debía ser pequeño en el sentido jurídico-económico, sino también en su poder coercitivo. Esto se debe a su convicción de que entre más grande sea el poder del estado menos cabida hay para individualidades fuertes. Lo inverso también es cierto: entre más pequeño el Estado, más individualidades fuertes. Justo por eso el diminuto estado premoderno era capaz de crear un número desproporcionado de individuos importantes. Gómez Dávila coincidiría con el juicio del suizo. 
Nos dice que "a medida que el estado crece el individuo disminuye" (Escolios I 21). Y estaba plenamente consciente de que la calidad del hombre también depende de factores políticos como el tamaño y la forma del estado. Los pequeños Estados aristocráticos son capaces de crear grandes individuos, mientras los grandes democráticos son máquinas de producción de hombresmasa. Por eso, el colombiano dice que "al derrumbarse, una aristocracia estalla en mil individuos vigorosos que dispara con violencia sobre la historia; una democracia, al desaparecer, se desinfla como un balón de caucho" (Notas 287). En ambos casos, pues, hay una preferencia por los estados premodernos con cierto poder despótico, pero sin una gran intervención burocráticoadministrativa en la vida diaria de las personas.

En suma, Gómez Dávila y Burckhardt parten del mismo presupuesto: el hombre es un ser caído. A partir de ese pesimismo antropológico desarrollan una lectura pesimista de la historia y una crítica de la modernidad. El hombre, en efecto, no es capaz de mejorar progresivamente la sociedad, dado que él mismo tiene una voluntad dañada por el pecado original. Los planes de reforma de la Ilustración deberían resultar en el fracaso. Sin embargo, ambos reconocen que hay instituciones más o menos propicias para la condición humana: el estado pequeño y no intervencionista. Uno podría interpelarlos y señalar que al menos podría deducirse de sus ideas que pasar de un Estado grande a uno pequeño y aristocrático debería considerarse un progreso. Pero tal vez son muy pesimistas para ello: ni siquiera en esa situación el hombre es capaz de redimirse, de superar su miseria. No hay eras doradas, aunque haya unas situaciones que no son tan horribles. Los anteriores son los pilares que ambos pensadores comparten y que, en efecto, muestran que Gómez Dávila tenía buenas razones para llamar santo patrón a Burckhardt.

\section{Montaigne}

Gómez Dávila y Montaigne están unidos por varios hilos que resultan cruciales desde una perspectiva vital, estilística y filosófica: su origen social, su estilo alejado de los estándares y prejuicios académicos y su escepticismo filosófico. Empecemos con el primero. Ambos pensadores venían de familias originalmente burguesas que habían alcanzado la cúspide social de su 
respectivo tiempo. La familia de Montaigne se había dedicado al comercio en tiempos de su bisabuelo y su padre, pero al comprar las tierras nobles en las que el escritor nació, esta pudo consolidar su estatus aristocrático. En consecuencia, el pensador francés vivió noblemente, i.e., administrando sus tierras y dedicándose a su vida intelectual (Langer 15).

Por su parte, la familia paterna del colombiano se había dedicado al comercio de telas y paños, logrando una fortuna considerable. Además, el padre de Gómez Dávila compró lo que equivalía a un título de nobleza entre los bogotanos de la época: una hacienda en la Sabana de Bogotá. Como dice López Michelsen, ninguna de las fortunas bogotanas "da posición social si no va acompañada de la compra de una propiedad en la Sabana" (121). El bogotano vivió noblemente, al menos en el contexto colombiano, administrando su hacienda, escribiendo y conversando con sus amigos. Como cuenta Francisco de Brigard, Gómez Dávila solo iba a sus almacenes de telas y a las juntas bancarias un par de veces a la semana (4). Los honores y la política, a diferencia de Montaigne, los desdeñó radicalmente: rechazó tanto la presidencia de la república, como embajadas en Europa.

Lo anterior podría verse como no más que una simple coincidencia biográfica y superficial, pero es el inicio de un acuerdo más profundo. Montaigne decía de sí mismo, y con orgullo, que no era un filósofo. La razón es que "Montaigne entiende por "filósofo" alguien indiferente al dolor y al placer, inhumanamente (y a veces cómicamente) persistente en sus convicciones" (Langer I). Gómez Dávila no negaba tajantemente que fuera un filósofo, pero se distanciaba al menos de los filósofos académicos. En sus Escolios, por ejemplo, dice que "en las universidades la filosofía meramente invierna" (118). De tal manera, prefería una aproximación propia a la filosofía, es decir, la vida filosófica:

Que la filosofía pueda parecer a algunos como una disciplina puramente intelectual, como un conjunto de conocimientos, como un grupo de investigaciones, es una singular aberración. La filosofía es una vida. La filosofía es una manera de vivir penetrada íntimamente de inteligencia y de razón, plenamente lúcida y ordenada hacia los objetos propios del espíritu (Notas 164).

Gómez Dávila, al igual que Montaigne, no es un filósofo en el sentido dominante de su propio tiempo. Se dedica a vivir de una manera penetrada 
por la inteligencia y la razón y no a escribir artículos académicos. ${ }^{2}$ Sus obras no cuentan con aparato bibliográfico, ni con revisión de pares, ni con el lenguaje propio de la universidad; de hecho, el bogotano ni siquiera tenía títulos universitarios que validaran su conocimiento. La ausencia de un espíritu propiamente académico en Gómez Dávila y Montaigne les hace compartir al menos cuatro elementos o rasgos que los unen. En primer lugar, a diferencia de la academia de su época, los Ensayos de Montaigne no son tratados de acuerdo a los principios tradicionales de su tiempo (Langer 2). Algo similar es posible decir de Gómez Dávila: a diferencia de los artículos universitarios, sus Escolios no desarrollan sistemáticamente un tema de acuerdo a las cuestiones propias del mundo universitario. Funcionan como un comentario de un texto implícito. El desarrollo de los temas existe, pero es asistemático, fragmentario, aforístico. Ya Goenaga y Barguil han visto un punto de conexión aquí entre Montaigne y Gómez Dávila, pues señalan que el ensayo de Montaigne de algún modo obedece a la misma lógica fragmentaria y subjetiva del escolio (107).

En todo caso, el problema del texto implícito también los conecta. Como señalan Verhelst y Raga, "los ensayos montaignianos son, a su vez, notas, en todo caso textos marginales" (240), justo como las de Gómez Dávila. ¿A las márgenes de qué? Al menos parcialmente de El discurso de la servidumbre voluntaria de La Boétie. "El texto del amigo, explícito en un primer momento, va ocultándose y convirtiéndose, cada vez más, en un texto implícito" (240). De algún modo, Gómez Dávila y Montaigne son comentaristas de un texto implícito. Lo que, por supuesto, también es posible en la academia, pero quizá no de la manera en que ambos lo hicieron.

En segundo lugar, tenemos uno de los rasgos más destacables de Montaigne: su encanto. Como dice Langer, "en parte, este encanto se deriva de la impresión del lector, justificada o no, de que en la mayoría de los capítulos de los Ensayos, Montaigne no está escribiendo para convencernos de una tesis en particular, de que no está intentando desarrollar un argumento" (7). En efecto, lo mismo podemos encontrar en Gómez Dávila: rara vez sentimos que está escribiendo para convencernos de una tesis en particular, de que está intentando desarrollar

2 La cuestión de la filosofía del colombiano como forma de vida ha sido desarrollada por Abad en su artículo "Gómez Dávila y la filosofía como forma de vida". 
un argumento. Por lo general, en cambio, se nos presenta como alguien que nos deja su testimonio, sus pensamientos, sin pretender nada más. Lo anterior no sería posible, empero, si ambos hubiesen sido profesores universitarios: en la academia hay que escribir para convencer, para ser citado, para tener impacto, para desarollar un argumento. No es que el encanto sea imposible, sino que el encanto que encontramos en Montaigne y Gómez Dávila es bien difícil de conseguir. El espíritu que provoca el encanto del colombiano queda bien sintetizado en uno de sus escolios:

No es una obra lo que quisiera dejar. Las únicas que me interesan se hallan a infinita distancia de mis manos. Pero un pequeño volumen que, de cuando en cuando, alguien abra. Una tenue sombra que seduzca a unos pocos. ¡Sí!, para que atraviese el tiempo, una voz inconfundible y pura (Notas 467).

En efecto, aquí nos dice que no ambiciona escribir grandes obras que cambien la historia de la filosofía. Su modestia lo obliga a abandonar esa empresa. Si sus escolios son citados en revistas Q1 también lo trae sin cuidado. Solamente quiere dejarnos el testimonio de su voz inconfundible y pura.

Un tercer elemento que ambos pensadores comparten es su amor por la excepción. "Montaigne desconfía de los juicios universales y parece enamorado de la excepción, del caso particular" (Langer 1). Aunque Gómez Dávila es adepto a hacer juicios fulminantes con pretensiones universales, también tiene amor por lo particular y excepcional. Por eso dice que "tan solo lo particular es interesante. ¡Pero cuántas particularidades sin interés!” (Escolios II 286). El amor a la excepción solo es posible en un ambiente intelectual en el que los autores no se ven obligados a buscar regularidades, leyes, coincidencias, como suele suceder en el discurso científico-académico. Lo que no quiere decir, empero, es que Gómez Dávila no encuentre válidos algunos juicios universales. Su teoría sobre la democracia, por ejemplo, es un juicio universal sobre todos los regímenes democráticos.

Un cuarto elemento es la presencia de los autores mismos en su obra. "Montaigne 'mismo' está siempre presente: reglas, pronunciaciones y observaciones, llevan una suerte de veto personal" (Langer 2). El Gómez Dávila de Notas, y en menor medida el de los Escolios, tiene un carácter similar. Nos suele hablar en primera persona, desde su posición particular, con el veto personal que ejerce sobre 
todo lo que le disgusta y con los laureles para todo lo que le agrada. Gómez Dávila nunca pretende hablarnos desde una perspectiva objetiva, desde un afuera de su propio yo, sino que, al contrario, insiste en que lo que el lector encuentra es su voz, i.e., la del autor.

El quinto y último elemento lo notó ya Rabier cuando señala que Montaigne y Gómez Dávila comparten un ethos de la modestia que se funda en no pretender ser completamente originales. Los dos pensadores basan su pensamiento en los autores de su biblioteca. Este se desarrolla en torno a la reflexión de lo que sus maestros han dicho (141). Los dos, pues, parten de una apropiación de los clásicos. Gómez Dávila y Montaigne citan los libros que admiran en su idioma original y con un propósito común: volver a las fuentes clásicas para alimentar el pensamiento propio (141). No quieren impresionar a nadie sino dialogar de primera mano con sus maestros. Esto haría parte de una tradición humanística en la que ambos se enmarcan. Pero no es solo una cuestión de cómo se manipula la materia prima. Sus citas también se parecen por algo que Rabier mismo notó: ninguno de los dos menciona siempre el origen de las citas. Esto implica un ocultamiento voluntario de las fuentes que despista a sus críticos (147).

Si pasamos al contenido filosófico de fondo encontramos una muy clara cercanía de ambos pensadores. En primer lugar, aunque existe un debate entre los comentaristas sobre la tendencia política y filosófica de Montaigne, una notable proporción se inclina por identificar un claro escepticismo, catolicismo y conservadurismo en su pensamiento. De manera similar, Gómez Dávila se describía a sí mismo del siguiente modo: "Sensual, escéptico y religioso, no sería quizá una mala definición de lo que soy” (Notas 345). Es preciso ver cómo es que se conectan para comprender el verdadero grado de cercanía entre sus pensamientos.

Montaigne ha sido llamado el fundador del escepticismo moderno (Hartle 183). Como dice Foglia, el encuentro del francés con Sexto Empírico lo impactó profundamente. Por eso, su medalla personal llevaba dos lemas escépticos: Epecho, que en griego significa "yo me abstengo", y que sais-je?, que en francés signfica “¿qué sé yo?". Aunque el alcance exacto del escepticismo dentro de su pensamiento sea objeto de disputa, está claro que Montaigne fue muy influenciado por el escepticismo antiguo (Verhelst y Raga 220). 
En sus Ensayos, encontramos que Montaigne frecuentemente nos muestra lo engañoso de nuestros razonamientos. De hecho, en varias ocasiones cambia de opinión para mostrarnos que ninguna es definitiva. El francés no tenía miedo de argumentar a favor de distintas posiciones. Por lo demás, al final de la Apología de Raimundo desarrolla un escepticismo muy fuerte, donde se cuestiona el valor de la opinión de los hombres y su incapacidad de llegar a la verdad. Eso contribuye a su devaluación de la razón, o más bien a la devaluación de nuestra confianza en que tenemos la razón y conocemos la verdad.

El escepticismo de Gómez Dávila, en cambio, es descrito por el autor del siguiente modo: "Mi escepticismo no es un rechazo de todo principio, de toda norma o de toda regla, sino la imposibilidad de recibir regla, norma o principio, de otras manos, y la necesidad de crearlos lentamente dentro del proceso de mi inmediato vivir" (Notas 109).

En principio, el escepticismo del Gómez Dávila de Notas parece de un cuño distinto al de Montaigne. No se basa tanto en una desconfianza de la capacidad humana de conocer la naturaleza de las cosas, como en la desconfianza que siente hacia los demás: su razón misma tiene que comprobar lo que otros le transmiten. En esto podría ser más cercano al Descartes del Discurso del método que a Montaigne. Sin embargo, en otros fragmentos del mismo libro aparece un escepticismo más fuerte, como bien lo notan Verhelst y Raga (138). En efecto, allí el colombiano constata la impotencia y esterilidad de su propia razón: "[...] cada idea que examino aumenta mi ignorancia y extiende mi incertidumbre" (Notas 205). En los Escolios va más allá: “[...] he visto la filosofía desvanecerse poco a poco entre mi escepticismo y mi fe" (127). En otras palabras, ya duda más radicalmente de la capacidad de la razón humana para conocer la naturaleza de las cosas. La filosofía es insuficiente: sus razonamientos se desvanecen mediante la crítica escéptica. Eso lo acercaría al escepticismo del pensador francés.

Para Montaigne el escepticismo es un arma religiosa. Este muestra que la razón carece de poder suficiente para cerrar disputas teológicas (Hartle 186). El conservatismo y la tradición encuentran así un aliado en el escepticismo de Montaigne. Esto es preciso explicarlo: el filósofo francés rehabilita la fe, dado que si la razón no sirve para decidirse en asuntos religiosos, entonces puede creerse sin necesidad de la razón. Para Gómez Dávila el escepticismo 
también es un arma religiosa. Por eso señala que "entre el escepticismo y la fe hay ciertas connivencias: ambos minan la presunción humana" (Sucesivos escolios 43). En efecto, ambos minan la presunción de que la razón humana se basta a sí misma para conocer el mundo. La fe le muestra al hombre que hay algo más allá de lo racional; el escepticismo le muestra a la razón sus límites. Así pues, trabajan juntas.

Ahora, es preciso explicar el conservadurismo de Montaigne. Al pensador francés se lo ha interpretado de muchas maneras: liberal, radical, conservador. Sin embargo, la vasta mayoría de comentaristas coinciden en que tiende hacia el conservatismo, por lo menos en el sentido de que, por lo general, Montaigne se oponía al cambio en la esfera política (Laursen 125). Estas interpretaciones se derivan en parte del libro I, capítulo XXII, “De la costumbre”. Allí el francés nos dice que nuestra conducta es básicamente el producto de la costumbre, no de una razón o verdad universales. De tal manera, esta tiene un poder enorme sobre nosotros. Necesitamos, de hecho, de la costumbre, de una regla, para poder vivir con nuestros semejantes. La razón no basta. Justamente por eso no podemos pretender reemplazar nuestras costumbres actuales por una supuesta razón universal que, en todo caso, está fuera de nuestro alcance. Incluso puede salir mal intentarlo. Como dice Oakeshott explicando a Montaigne: "Que sais-je: ¿de qué estoy tan seguro que dirigiría toda la energía y actividad de la humanidad para alcanzarlo? Sacrificar el modesto orden de la sociedad por la unidad moral o 'verdad' (religiosa o secular) es sacrificar lo que necesitamos por una quimera" (76). Quizá, empero, habría que matizar esa interpretación por medio de otros pasajes donde Montaigne sí supone que podemos acceder a ciertos estándares de la razón. Por ejemplo, cuando dice que:

Quien pretenda desembarazarse de este violento prejuicio de la costumbre hallará muchas cosas que, a pesar de estar aprobadas e indubitablemente recibidas, no tienen otro fundamento que la nevada barba y faz rugosa del uso, que las ha dado su autoridad; arrancada esta careta, conduciendo las cosas a la verdad y a la razón, sentirá su juicio como trastornado y, sin embargo, llevado a situación más firme (I, XXII).

En todo caso, la interpretación dominante apunta a que en Montaigne encontramos, al menos en la esfera política, una deferencia por la tradición. Pero no se deriva de la justicia que esta pueda encerrar, sino del escepticismo: 
sabemos tan poco sobre cómo mejorar nuestra situación de manera segura, que es preferible contentarnos con lo que tenemos, i.e., con nuestros modestos logros. En Gómez Dávila encontramos una actitud similar. Por eso nos señala que "aún en Arcadia es prudente vigilar a los soñadores de utopías" (Escolios II 43). Evidentemente, desde su posición no debemos desconfiar solo de quienes pretenden sacrificar nuestro modesto e injusto orden, sino que deberíamos ponernos en guardia incluso frente a quienes pretenden abolir las sociedades idílicas en nombre de un más alto ideal. Todo esto se origina también en un escepticismo que duda de la capacidad de la razón para conocer y poner en marcha el mejor orden. Gómez Dávila solo confía en lo que la historia trae lentamente, i.e., en la tradición. Por eso, "el reaccionario no respeta todo lo que trae la historia, pero respeta solamente lo que trae" (Escolios II 85).

En suma, Gómez Dávila comparte un origen social equivalente al de Montaigne en su propia sociedad: su familia se enriqueció mediante el comercio y eso le permitió llevar un estilo de vida noble. Ambos son escépticos, aunque tengan diferencias en el origen y el alcance de sus escepticismos. Hasta donde sabemos, en efecto, el escepticismo de Gómez Dávila no tiene su origen directo en los antiguos, sino que se conecta más fácilmente con la tradición de escepticismo católico de la que Montaigne podría ser considerado el fundador. A los dos pensadores la duda les sirve para contrarrestar las pretensiones de una razón que se juzga absoluta y certera: si la razón falla o es insuficiente para tener certezas metafísicas, la fe es válida. Y también les sirve para justificar el valor de la tradición por encima de grandes planes racionales y abstractos para mejorar la sociedad. Por eso, tanto Montaigne como Gómez Dávila se conectan con la tradición conservadora, incluso aunque lo hagan de una manera problemática.

\section{Conclusiones}

Burckhardt y Montaigne son hilos que Gómez Dávila usa para tejer su crítica a la modernidad. El suizo sin duda no le enseñó el dogma del pecado original, dado que Gómez Dávila era un católico de viejo cuño. Pero sí le confirmó su importancia para leer la historia de un modo pesimista. Le quitó toda esperanza en que el hombre pudiese liberarse y construir una sociedad a la medida de sus sueños. El proyecto moderno-ilustrado que pretende hacer progresar a la 
humanidad le resulta, por tanto, ingenuo y sobre todo peligroso. Esto viene a ser reforzado por el escepticismo de Montaigne. ${ }^{3}$ No es solo, en efecto, que el hombre sufra las consecuencias del pecado original, sino que además el escepticismo del francés le hace pensar al colombiano que la razón misma no tiene suficiente capacidad para decidir cómo deberíamos transformar nuestra sociedad. La verdad se nos escapa. Por lo tanto, deberíamos habernos quedado con las sociedades tradicionales que vivían de acuerdo con la costumbre. Esta idea no solo aparece en los Escolios, sino que también es uno de los puntos centrales en "De Iure".

Montaigne y Burckhardt son pensadores conservadores. Pero la suma de sus argumentos lleva a Gómez Dávila a ser reaccionario, es decir, a impugnar totalmente el proyecto de la modernidad: nada de él vale la pena ser conservado. En efecto, si no son posibles las edades doradas, si el hombre no es capaz de superar su miseria porque su naturaleza está corrompida - y además la historia lo confirma-, y si sabemos muy poco sobre cómo mejorar nuestra condición, la conclusión es que el mundo moderno-progresista es un error radical. Es decir, la raíz del progreso es errónea, dado que se basa justamente en una idea falsa: en que el hombre es capaz de superar su miseria por medio de una razón y un conocimiento (científico, técnico, sociológico, económico, etc.) que le indica cómo debería vivir cada vez mejor. El progreso también supone que la voluntad del hombre no tiene ninguna mancha: es perfectamente posible usar el conocimiento sin que haya algo en nuestra voluntad que lo lleve al mal. Gómez Dávila se opone a estas ideas.

Así pues, lasuma delos pensamientos delfrancésyel suizo lleva alcolombianoa una posición reaccionaria: es preciso rechazar totalmente las pretensiones del mundo moderno. Y, sin embargo, dado que somos seres caídos, el colombiano no tiene muchas esperanzas en que la sola acción humana pueda transformar el mundo para bien. En consecuencia, rechaza la política como medio para implementar sus ideas. Su reaccionarismo sería una impugnación y una resignación basada en el pesimismo de Burckhardt y el escepticismo de Montaigne.

3 Michael Rabier ha notado que, pese a la inmensa influencia de Francia y Montaigne en el pensamiento del colombiano, ese mismo país no se ha interesado mucho en Gómez Dávila. 
La intertextualidad que se acaba de mostrar nos abre los ojos frente a un aspecto importante de Gómez Dávila. El colombiano no era un mero glosador de textos aleatorios, un simple ocioso que comentaba en sus cuadernos cualquier cosa que caía en sus manos. Al contrario, hay una serie de ideas que forman su visión de mundo y a partir de las cuales va interpretando la modernidad. Gómez Dávila se apropia de sus maestros para sus ejercicios hermenéuticos. Montaigne y Burckhardt nos permiten, por tanto, acercarnos a la pintura que los escolios van construyendo.

Los escolios tienen una sensibilidad y unos afluentes que los unen. En el pesimismo de Burckhardt y en el escepticismo de Montaigne podemos encontrar dos de las más importantes influencias en el colombiano. En efecto, incluso Gómez Dávila llegaría a decir que Burckhardt es uno de los pocos hombres verdaderamente adultos en la historia (Escolios II 132). Tal vez lo decía porque su lectura pesimista de la humanidad lo libró de los infantilismos utópicos. Eso no quiere decir, como se ha visto, que Gómez Dávila no tomara distancia frente a algunas ideas del suizo y del bordolés. Pero sí quiere decir que su influencia se deja ver en las páginas de los escolios y en su visión de mundo, a tal punto que termina circunscribiendo su identidad, i.e., el reaccionarismo.

\section{Referencias}

Abad Torres, Alfredo. Pensar lo implícito: en torno a Gómez Dávila. Pereira: Centro de Recursos informáticos y Educativos - CRIE, 2008.

Abad Torres, Alfredo. "Gómez Dávila y la filosofía como forma de vida". Revista Boletín Redipe, 8.1 (2019): 53-61. Disponible en: http://revista.redipe.org/index. $\mathrm{php} / 1 /$ article/view/671.

Burckhardt, J.C. Reflexiones sobre la historia universal. Medellín: Fondo de Cultura Económica, 1996.

Burckhardt, J.C. Judgments on history and historians. Indianapolis: Liberty Fund, 1999. Galindo, M. "Un pensador aristocrático en los andes: Una mirada al pensamiento de Nicolás Gómez Dávila”. Historia Crítica, 19(2000): 13-23.

Goenaga y Barguil. "El eclecticismo de un estilo". En: Mejía, J.F. (ed). Facetas del pensamiento de Nicolás Gómez Dávila. Bogotá: Editorial Pontificia Universidad Javeriana / Instituto Caro y Cuervo, 2018. Disponible en: https://drive.google.com/ file/d/16gYz5Ywlxi-wUoh6DnSEbQa9xqGtWhYI/view. 
Gómez Dávila, Nicolás. Escolios a un texto implícito. Tomo I. Bogotá: Colcultura, 1977. Gómez Dávila, Nicolás. Escolios a un texto implícito. Tomo II. Bogotá: Colcultura, 1977. Gómez Dávila, Nicolás. Sucesivos escolios a un texto implícito. Tomo I. Bogotá: Colcultura, 1992.

Gómez Dávila, Nicolás. "El reaccionario auténtico". Revista de la Universidad de Antioquia, 240, (1995): 477-505.

Gómez Dávila, Nicolás. Escolios a un texto implícito (selección). Bogota: Villegas, 2001. Gómez Dávila, Nicolás. Textos I. Bogotá: Villegas Editores, 2002.

Gómez Dávila, Nicolás. Notas. Bogotá: Villegas Editores, 2003.

Gómez Dávila, Nicolás. Escolios a un texto implícito. Tomo I. Bogotá: Villegas, 2005.

Gómez Dávila, Nicolás. Escolios a un texto implícito. Tomo II. Bogotá: Villegas, 2005.

Gómez Dávila, Nicolás. Nuevos escolios a un texto implícito. Tomo I. Bogotá: Villegas, 2005.

Gómez Dávila, Nicolás. Nuevos escolios a un texto implícito. Tomo II. Bogotá: Villegas, 2005.

Gómez Dávila, Nicolás. Sucesivos Escolios a un texto implícito. Tomo I. Bogotá: Villegas, 2005.

Gómez Dávila, Nicolás. “De Iure” (T. Molina, Trad.). Revista Nova Et Vetera. (2017) Disponible en: https://www.academia.edu/34702433/De_Iure_-_Nicolás_Gómez_ Dávila_Bilingual_edition_

Foglia, M. "Michel de Montaigne". Agosto 18, 2004. Tomado de: https://plato.stanford. edu/entries/montaigne/.

Langer \& Hartle. The Cambridge companion to Montaigne. Cambridge: Cambridge Univ. Press, 2016.

Laursen, John Christian. The politics of skepticism in the ancients, Montaigne, Hume, and Kant. Vol. 35. Brill, 1992.

Michelsen, Alfonso López. Los elegidos. Oveja Negra, 1999.

Montaigne. Ensayos. Tomado de: http://www.cervantesvirtual.com/obra-visor/ ensayos-de-montaigne--0/html/fefb17e2-82b1-11df-acc7-002185ce6064_82. html\#I_0_

Mosebach, M. "Un ermitaño en las orillas del mundo habitado -Sobre Nicolás Gómez Dávila” (T. Molina, Trad.). Revista Nova Et Vetera, 3.29 (Agosto 29, 2017).

Oakeshott, M. The politics of faith and the politics of scepticism. New Haven, CT: Yale University Press, 1996.

Pizano de Brigard, Francisco. Semblanza de un colombiano universal \& Conversaciones con Nicolás Gómez Dávila. Bogotá: Uniandes, 2013.

Rabier, M. "Biblioteca gomezdaviliana: las fuentes bibliográficas del pensamiento de Nicolás Gómez Dávila”. Revista Interamericana de Bibliotecología, 36.3 (2013): 235248.

Rabier, M. "La 'cuestión literaria' en la obra de Nicolás Gómez Dávila”. Revista Perífrasis, 5.10 (2014).

Rabier, M. "Nicolás Gómez Dávila y las paradojas del conservadurismo." La Razón Histórica, 26 (2014). 
Rabier, M. "Sobre un modo gomezdaviliano de escribir (y de leer)". En Mejía, J.F. (ed). Facetas del pensamiento de Nicolás Gómez Dávila. Bogotá: Editorial Pontificia Universidad Javeriana / Instituto Caro y Cuervo, 2018. Disponible en: https://drive. google.com/file/d/16gYz5Ywlxi-wUoh6DnSEbQa9xqGtWhYI/view.

Rabier, M. "Una cierta idea de la filosofía. Acerca de la recepción y no recepción de Nicolás Gómez Dávila en Francia”. Revista Filosofía UIS, 18.1 (enero-junio 2019). Disponible en: https://revistas.uis.edu.co/index.php/revistafilosofiauis/article/ view/8657.

Roderick, J. Jacob Burckhardt and the Crisis of Modernity. Montreal: McGill-Queens University Press, 2000.

Verhelst Montenegro, S., y Raga Rosaleny, V. "Similitudes entre el escepticismo de los Ensayos de Montaigne y las Notas de Nicolás Gómez Dávila". Eidos, 28.28 (2017).

Volpi, F. "El solitario de Dios". En Nicolás Gómez Dávila. Escolios a un texto implícito. Tomo I. Bogotá: Villegas, 2005. 